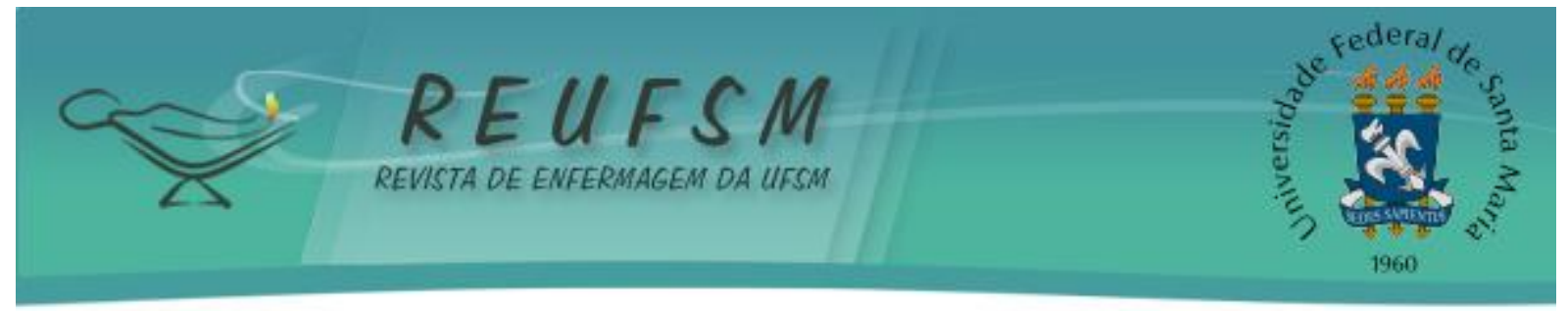

REVISÃO

\title{
O CUIDADO HUMANIZADO EM UNIDADE DE TERAPIA INTENSIVA: UMA REVISÃO BIBLIOGRAFICA
}

THE HUMANIZED CARE IN INTENSIVE CARE UNITS: A LITERATURE REVIEW

\section{EL CUIDADO HUMANIZADO EN UNIDADES DE TERAPIA INTENSIVA: UMA REVISIÓN DE LA LITERATURA}

\author{
Silviamar Camponogara ${ }^{1}$ \\ Tanise Martins dos Santos ${ }^{2}$ \\ Margor Agathe Seiffert ${ }^{3}$ \\ Camila Neumaier Alves ${ }^{4}$
}

RESUMO: 0 estudo objetivou conhecer que publicações têm sido divulgadas, na área da enfermagem, a cerca da humanização em Unidade de Terapia Intensiva (UTI). Constitui-se em uma revisão sistemática, cujos dados foram coletados nas bases de dados LILACS e BDENF, com recorte temporal entre 2000 a 2009. Após leitura do material foi realizada categorização e discussão dos dados. Os resultados evidenciam que quatro temas são destacados com maior relevância na produção científica: o ambiente da Unidade de Terapia Intensiva; uso de tecnologias em detrimento do cuidado; o trabalhador como protagonista da humanização em UTI; dificuldades vivenciadas pela equipe de enfermagem para implementar a humanização na UTI. A humanização é apontada como forma de resgatar a dignidade humana, mas somente será realidade se for compreendida sua real importância e os profissionais se sentirem protagonistas desse processo na UTI.

Descritores: Equipe de enfermagem; Unidade de terapia intensiva; Humanização da assistência.

ABSTRACT: This study aimed to know which publications in the nursing area have been released about the humanization in Intense Care Units (ICU). This work is constituted of a systematic review, whose data were collected from the databases LILACS and BDNEF, during the period of the year 2000 to 2009. After the material was read, a categorization of the data was done and they were discussed. The results show that four topics appear more relevantly in the scientific production: the environment of the Intensive Care Unit; the use of technologies more than the care itself; the professional as the leading role of the humanization process in ICU; difficulties undergone by the nursing staff to implement the humanization in ICU. The humanization is pointed out as a way to rescue the human dignity, but that will only become reality if its real importance is understood and if the professionals feel as leading roles of this process in ICU.

Descriptors: Nursing staff, Intensive care unit; Humanization in health care.

RESUMEN: Este estudio tuvo como objeto conocer que publicaciones han sido difundidas, en el área de enfermería, sobre la humanización en Unidades de Terapia Intensiva (UTI). En este trabajo, cuyos datos se recolectaron en las bases de datos LILACS y BDENF, se

\footnotetext{
${ }^{1}$ Enfermeira. Doutora em Enfermagem. Professora Adjunta do Departamento de Enfermagem da Universidade Federal de Santa Maria. E-mail: silviaufsm@yahoo.com.br

2 Enfermeira. Mestranda do Programa de Pós-Graduação em Enfermagem da Universidade Federal de Santa Maria. E-mail: tanisems@yahoo.com.br

${ }^{3}$ Acadêmica do $8^{\circ}$ semestre do Curso de Graduação em Enfermagem da Universidade Federal de Santa Maria. Email: margotenfer@gmail.com

${ }^{4}$ Acadêmica do $8^{\circ}$ semestre do Curso de Graduação em Enfermagem da Universidade Federal de Santa Maria. Email: camilaenfer@gmail.com
} 


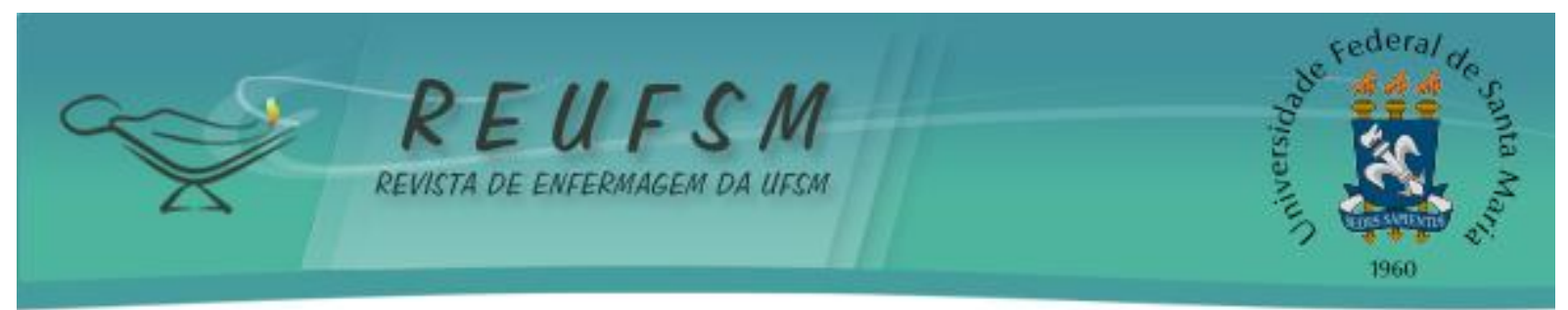

realizó una revisión sistemática, con un recorte temporal entre los años 2000 y 2009. Después de la lectura del material, se realizaron la categorización y discusión de los datos. Los resultados muestran que se destacan con mayor relevancia cuatro temas en la producción científica: El ambiente de La Unidad de Terapia Intensiva; el uso de tecnologías en detrimento de cuidados; el trabajador como protagonista de la humanización en UTI; dificultades vividas por el equipo de enfermería para implementar la humanización en la UTI. Se señala la humanización como forma de rescatar la dignidad humana, pero solamente será realidad cuando se comprenda su real importancia y los profesionales se sientan protagonistas de este proceso en la UTI.

Descriptores: Equipo de enfermería; Unidad de terapia intensiva; Humanización de la asistencia

\section{INTRODUÇÃO}

A Unidade de Terapia Intensiva (UTI) é um ambiente hospitalar destinado a pacientes graves, porém que apresentem um quadro clínico recuperável. É um ambiente de profissionais qualificados, com alto aparato tecnológico e assistência contínua. ${ }^{1} 0$ ambiente da UTI transparece gravidade, invasividade e risco de morte, além de aparentar ser hostil, negativo e distante da produção de saúde. ${ }^{2}$

Neste setor atuam diversos profissionais, das mais variadas áreas, dentre estes, destacamos os profissionais de enfermagem, que são os responsáveis por muitas atividades relacionadas ao cuidado intensivo, tais como: a realização de diversos procedimentos, a constante monitorização dos pacientes, o uso de aparelhagens diversas, a atuação em situações de emergência. Diante desse contexto, a coexistência de um trabalho mecanizado e do cuidado humanizado pode ficar ameaçada, resultando em crescente desumanização. Nestas situações, tudo deve estar pronto e no lugar muito rápido, o que leva a uma valorização da tecnologia, impedindo que o profissional torne-se mais sensível, crítico e humanizado frente à situação do paciente. ${ }^{2} 0$ cuidado prestado pela equipe de enfermagem em UTI ainda é orientado pelo modelo biomédico, em que a atenção é voltada para a doença e para os procedimentos técnicos, e não voltado aos sentimentos e receios do paciente e seus familiares. ${ }^{3}$

Neste sentido, muitos estudos ressaltam que, embora o profissional de enfermagem esteja envolvido nesse mundo de cabos, fios e condutores, atento a cada alteração, não deve perder de vista o foco principal do seu trabalho: o cuidado ao paciente. ${ }^{1}$ Nos últimos anos, tem-se obvervado um crescimento e aperfeiçoamento de políticas e ações que promovam a humanização da assistência, não só na UTI, mas no contexto de atenção a saúde como um todo. Dentre estas ações, podemos citar o Programa Nacional de Humanização da Assistência Hospitalar (PNHAH), instituído pelo Ministério da Saúde em 2001. O PNHAH propõe um conjunto de ações integradas que visam mudar substancialmente o padrão de assistência ao usuário nos hospitais públicos do Brasil, melhorando a qualidade e a eficácia dos serviços prestados por estas instituições. Seu objetivo é aprimorar as relações entre o profissional de saúde e o usuário, dos profissionais entre si e do hospital com a comunidade. ${ }^{4}$

Além disso, o PNHAH enfatiza que, a humanização, abrange circunstâncias sociais, éticas, educacionais e psíquicas que estão presentes no relacionamento humano. Significa resgatar o respeito à vida humana, privilegiando a objetividade, generalidade, causalidade e a especialização do saber, ao mesmo tempo em que se valoriza os sentimentos, indissociando os aspectos emocionais e físicos. ${ }^{4}$

A humanização deve fazer parte da filosofia e da prática da enfermagem, nos diversos cenários em que atua, especialmente nas UTIs. Os recursos materiais e os 


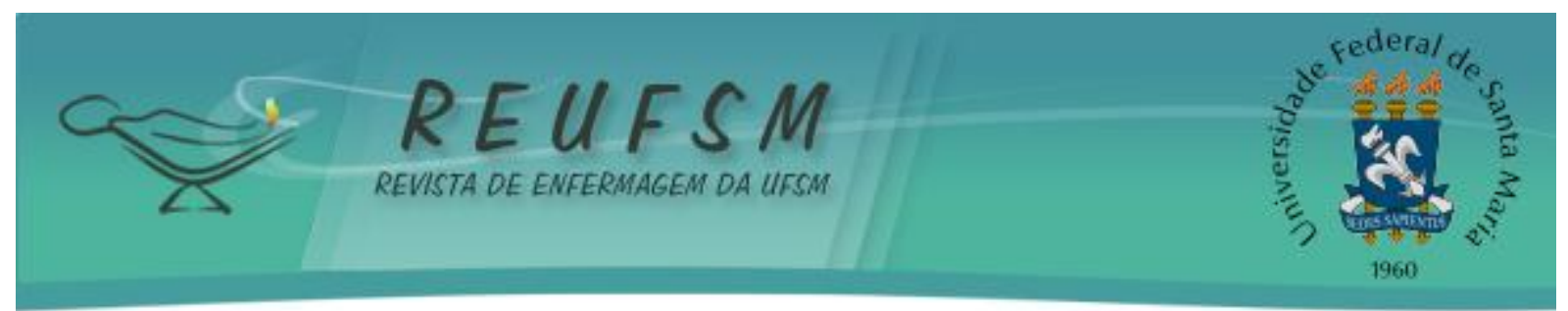

instruementais são muito importantes na UTI, porém, não são mais significativos que a essência humana. É esta essência que guiará o pensamento e as ações da equipe de enfermagem, tornando-a capaz de criticar e construir uma realidade mais humana, menos agressiva e hostil aos indivíduos que convivem, diariamente, na UTI. ${ }^{5}$

Diante do exposto, este estudo tem como objetivo conhecer que publicações têm sido divulgadas, na área da enfermagem, a cerca da humanização em UTI, entendendo que, poderá contribuir para a construção de conhecimentos e para a prática profissional, uma vez que, apesar de ser um tema já abordado na área, ainda encontra dificuldades para ser implementado, especialmente, em UTI.

\section{MÉTODO}

Trata-se de uma revisão sistemática, a qual se constitui em uma síntese de estudos primários, incluindo uma busca de dados abrangente, com utilização de critérios de seleção explícitos e rigorosos, metodologia clara e sistematizada, bem como, uso de critérios uniformes de avaliação. ${ }^{6}$ Para tanto, realizou-se uma busca de artigos indexados na Biblioteca Virtual de Saúde (BVS), nas bases de dados LILACS e BDENF. Como descritores foram utilizados: "Unidade de Terapia Intensiva", "Equipe de Enfermagem" e "Humanização da Assistência". Os dados foram coletados no período de outubro de 2009. Os artigos que serviram para a construção do estudo compreendem publicações do ano de 2000 a 2009 (sendo este último incompleto, visto que ainda não havia findado). Constituíram-se em critérios de inclusão: artigos nacionais e disponíveis em texto completo, versando sobre humanização do cuidado em UTI adulto. Os critérios de exclusão, por sua vez, foram: artigos internacionais e não estar disponível em texto completo, teses, dissertações, livros e outros informativos.

Para a análise dos dados realizou-se, primeiramente, uma leitura flutuante dos artigos selecionados, num primeiro momento pelos resumos dos mesmos, para que fosse reconhecido o conteúdo dos artigos, após, iniciou-se uma leitura aprofundada, buscando compreender os principais achados dos estudos na íntegra. Os dados foram caracterizados quanto ao ano de publicação, periódico de publicação, abordagem e tipo de pesquisa. A seguir, agruparam-se os dados encontrados em diferentes categorias de análise, realizando-se, por fim, discussão.

De um total de 47 artigos, apenas onze constituíram-se em material de análise, tendo em vista os critérios de inclusão e exclusão previstos e as repetições nas bases de dados. A partir da análise dos textos encontrados, emergiram as seguintes categorias de análise: o ambiente da Unidade de Terapia Intensiva; uso de instrumentais tecnológicos em detrimento do cuidado; o trabalhador como protagonista da humanização em UTI; dificuldades vivenciadas pela equipe de enfermagem para implementar a humanização na UTI.

\section{RESULTADOS}

De uma forma geral, verifica-se que, dada a importância da temática, a produção científica sobre humanização em UTI, ainda é pequena. A maioria dos artigos foi publicada a partir de 2006, em diferentes periódicos da área da enfermagem, constituindo-se, a maior parte, em pesquisas de campo, com abordagem qualitativa.

Segundo a maioria dos estudos, o ambiente da Unidade de Terapia Intensiva é destinado à pacientes graves, porém que apresentem um quadro clínico recuperável. Essa unidade surgiu da necessidade de aperfeiçoamento das instrumentais tecnológicos e do aprimoramento das habilidades dos profissionais para o atendimento a pacientes críticos, 


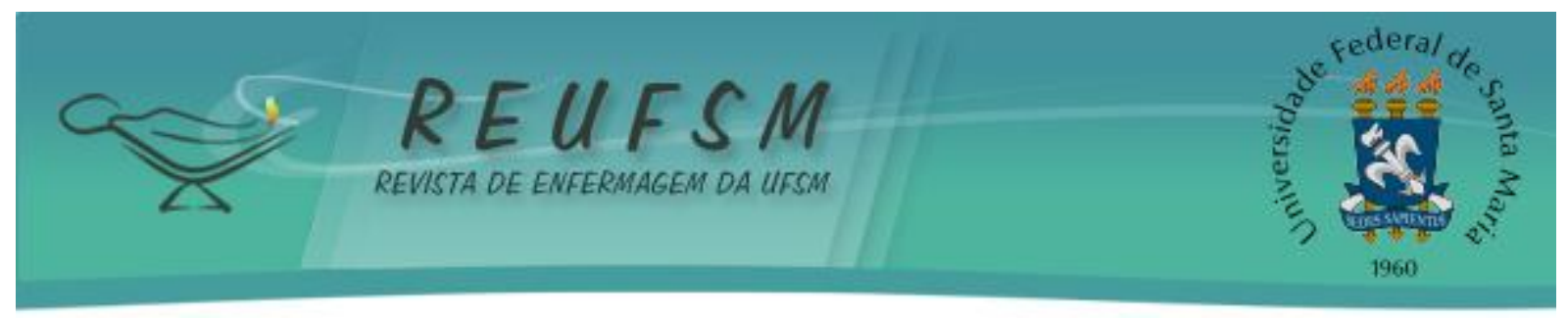

com necessidades de cuidados complexos. A UTI é considerada um dos ambientes mais agressivos e tensos do hospital, onde a morte é uma constante, devendo, os profissionais, estar sempre alertas para qualquer intercorrência. Também são destacadas questões como: privação de sono, ruídos excessivos, invasão de privacidade, grande fluxo de profissionais, da quase exclusão dos familiares no processo de cuidado, de pouca comunicação, e de inúmeros cabos, fios e monitores. ${ }^{1}$

A UTI possui algumas características próprias, como a convivência diária dos profissionais e dos sujeitos doentes com as situações de risco, a ênfase no conhecimento técnico-científico e no instrumental tecnológico para o atendimento biológico, a ansiedade dos pacientes e dos familiares e trabalhadores de saúde, as rotinas rígidas e inflexíveis, e a rapidez de ação no atendimento ${ }^{3}$. Tendo em vista esse contexto, as publicações apontam para a necessidade dos trabalhadores possuírem características especiais, no sentido de poderem prestar o cuidado, da melhor forma possível, apesar das 'adversidades' desse ambiente de trabalho. ${ }^{7}$

Com relação ao uso de instrumentais tecnológicos em detrimento do cuidado humanizado, os resultados das publicações têm demonstrado que, a utilização dos instrumentais tecnológicos de forma inadequada e a falta de compromisso de alguns profissionais, contribuem para tornar a assistência mecanicista, gerando o afastamento do paciente e da família da equipe multiprofissional, descaracterizando o cuidado como ação humana. O cuidador de enfermagem em UTI, na maioria das vezes, esquece de tocar, conversar e ouvir o ser humano que está à sua frente envolvido pela rotina diária complexa e pela prestação de serviço de alta tecnologia. ${ }^{5}$

Os profissionais de saúde têm dificuldade de diferenciar o ser humano das máquinas e aparelhos, os quais são responsáveis pela sua sobrevivência, transformando sua relação com a máquina e o cuidado de enfermagem num ato mecânico, vendo o paciente como meramente uma extensão dos aparelhos. Os autores ressaltam que, os equipamentos favorecem o atendimento imediato, proporcionam segurança para toda a equipe da UTI, porém, podem contribuir para tornar as relações humanas mais distantes, fazendo com que o paciente e seu familiar sintam-se abandonados. Muitas vezes, os profissionais sabem mais sobre a máquina e pouco sobre o ser humano que estão cuidando. ${ }^{8}$

0 cuidado de enfermagem acontece nesse conturbado ambiente de aparelhagens múltiplas, desconforto, impessoalidade, falta de privacidade, dependência da tecnologia, isolamento social, negatividade, solidão, frieza e possibilidade de morte. ${ }^{3}$ Dessa forma, a evidência de que a intensa utilização de recursos tecnológicos interfere na forma como o cuidado é desenvolvido nestes setores é contundente. Alguns autores, no entanto, apresentam um entendimento um pouco diferenciado, manifestando que, o instrumental tecnológico não é benéfico nem maléfico, depende da forma como é utilizado. Reforçam que o aparato tecnológico deve ser utilizado de forma criativa e humana para melhorar a qualidade de vida. ${ }^{9}$

Por outro lado, são relevantes, para as publicações analisadas, a temáticas relacionadas ao trabalhador como protagonista da humanização em UTI. Dentre as significações de humanização, por parte da equipe, há destaque para questões como: o resgate da dignidade humana e cuidar ao próximo como gostariam que fossem cuidados; ${ }^{4,10}$ a idéia de cuidar, servir e tratar dos pacientes de forma afetuosa, com atenção, cortesia, delicadeza, prontidão, solicitações e comunicação efetiva, ${ }^{9}$ a relação com sentimentos de respeito e dignidade pelo paciente e familiares. Os profissionais da equipe de enfermagem também relacionam a humanização em saúde com uma política que propicia o resgate de características humanas, durante o ato de cuidar, como a empatia. ${ }^{11}$

Alguns autores consideram que, quando se pensa em humanização, no âmbito institucional, primeiramente pensamos nos usuários e, apesar de muito discutir-se sobre a 


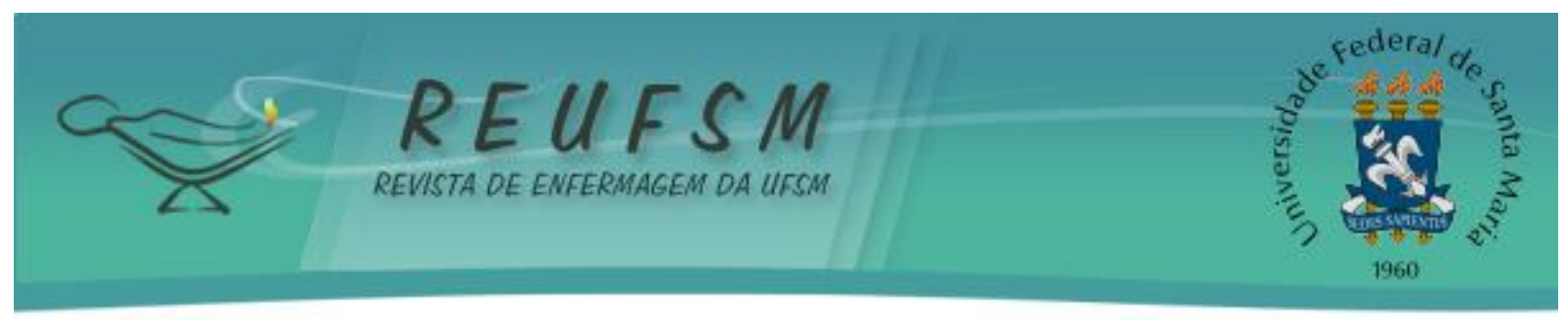

humanização hospitalar, o bem-estar dos profissionais da saúde tem sido deixado em segundo plano. Estudo realizado com a equipe de enfermagem que atua em uma UTI, revela que alguns entrevistados encontram-se sensibilizados quanto à compreensão do conceito "humanizar", mas afirmam ser muito enfatizada a figura da pessoa-paciente, sendo disponibilizada pouca atenção ao cuidado e a humanização do sujeito-trabalhador. ${ }^{12}$

Apesar de muitos estudos atrelarem a humanização a questões relacionais do ser humano, outros enfatizam aspectos diferentes, como a integralidade. ${ }^{2}$ A humanização deve ser projetada para além destes aspectos do humanismo, uma vez que considera a necessidade não só de melhorar o acesso, o acolhimento e o cuidado prestado, mas também o modo de gerir e administrar as práticas de saúde com vistas a qualificar os serviços. ${ }^{10}$

A inserção da família também foi muito mencionada em estudos, como parte integrante do processo de humanização. A família, extensão do doente, com quem ele contava em vários momentos de sua vida, é afastada do seu convívio, por imposição das rotinas do serviço, geralmente rígidas. 0 estar na UTI rompe bruscamente com o modo de viver do sujeito, incluindo suas relações e seus papéis. ${ }^{3,8}$

Com base nas publicações que compuseram esse estudo, depreende-se que a equipe de enfermagem, conhece os aspectos a serem considerados, para que a humanização seja incorporada no cotidiano da UTI. No entanto, parece haver uma lacuna entre o discurso e a prática. Uma das investigações realizadas aponta que, os momentos de contato entre paciente e equipe, estavam relacionados às atividades como banho, aspiração endotraqueal, curativos, mudança de decúbito. 0 contato com a família ocorria de maneira bastante formal e burocrática. O diálogo com os familiares era restrito e, no momento de visitas, os funcionários não se faziam presentes, fazendo com que o sofrimento e a angústia dos familiares aumentassem. ${ }^{5}$

As publicações também demarcam dificuldades vivenciadas pela equipe de enfermagem para implementar a humanização na UTI. De uma forma geral, revelam que os fatores que dificultam o processo de humanização estão relacionados ao modo de cuidar, ainda fundamentados no modelo cartesiano de atenção, às relações interpessoais entre os membros da equipe de saúde e às normas e rotinas estabelecidas pelos serviços de saúde. ${ }^{3}$ Além disso, apontam como obstáculos para a humanização os fatores estressantes no trabalho da enfermagem, quais sejam: o lidar com o sofrimento do paciente e da família, o fazer específico da profissão (que requer agilidade, atenção e renovação de conhecimentos técnicos), a necessidade de improvisação, as questões de ordem burocrática, o inter-relacionamento com a equipe e o barulho constante dos aparelhos. ${ }^{10}$

A rotina de trabalho, para grande parte dos profissionais, se mostra insatisfatória e até frustrante, ocorrendo uma lacuna em relação aos papéis mal definidos entre a equipe de enfermagem, deixando a desejar as potencialidades de cada profissional. 0 enfermeiro, na equipe multidisciplinar, continua sendo visto como mero cumpridor de tarefas, ficando aquém de outros profissionais, no que tange à autonomia e ao conhecimento científico, dada a falta de incentivo e sobrecarga de trabalho. ${ }^{1}$

Pesquisas mostram que, o serviço de enfermagem, como um grupo organizado de pessoas, no qual é grande o número e a diversidade das atividades, muitas vezes, apresenta um trabalho normativo que corresponde a regras institucionais, dificultando a capacidade de inovação e adaptação dos profissionais a novas situações e mudanças do ambiente, pois o trabalho normativo se distancia muito do trabalho executado realmente. ${ }^{8}$ Além disso, os baixos salários, a dificuldade na conciliação da vida familiar e profissional, a jornada de trabalho, muitas vezes, dupla ou tripla, ocasionando sobrecarga de atividades e cansaço, e o contato constante com pessoas sob tensão, raramente, são trazidos para o debate sobre humanização. ${ }^{13}$ 


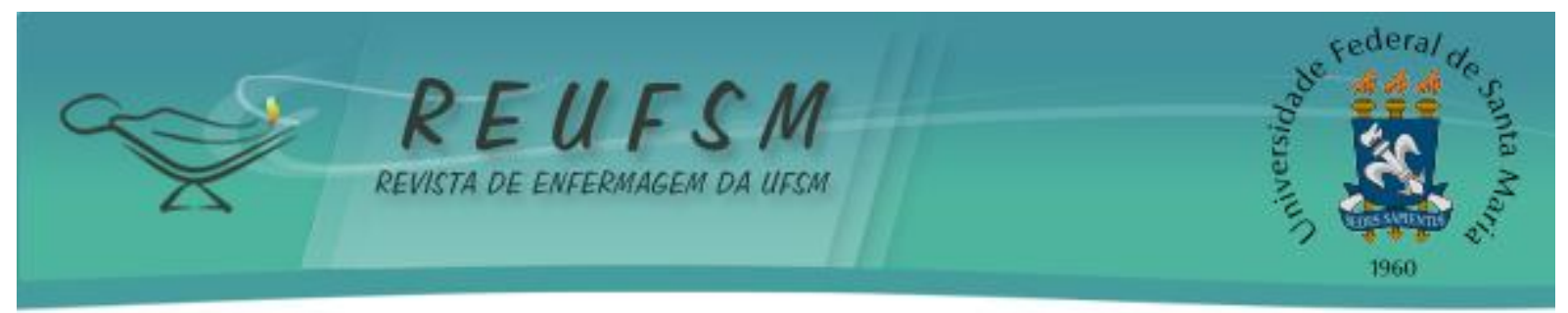

Esse contexto aponta para a reflexão sobre a necessidade de repensar-se a rotina de trabalho da equipe de enfermagem, particularmente no que tange as inúmeras dificuldades enfrentadas no cotidiano laboral. Nesse sentido, as publicações demarcam que o trabalho é fundamental, devendo ser encarado como fonte de prazer e satisfação e não de sofrimento, por isso, além das mudanças internas nos trabalhadores, são necessárias alterações no ambiente de trabalho e nas relações interpessoais que deveriam estar baseadas no amor ao próximo, para que a humanização possa se tornar uma realidade no cotidiano. $^{12}$

Outro estudo evidencia a falta de qualificação dos profissionais, como um fator que impede a implementação da humanização na UTI, por parte da equipe de enfermagem. É necessário reorientação e revisão dos currículos que formam tais trabalhadores, pois não basta a existência de uma política transversal, como a da humanização, se não houver profissionais competentes e comprometidos com as mudanças nos serviços de saúde. ${ }^{10}$

Outro fato muito constatado nas falas da equipe de enfermagem, em um estudo realizado com esses profissionais, foi o não envolvimento com os pacientes e familiares, como forma de mecanismo de defesa adotados pela equipe, no intuito de não criar vínculo e não vir a sofrer com a situação em que o paciente se encontra. Os autores do estudo acreditam que, o envolvimento com o paciente e a família é um pré-requisito essencial para humanizar. Porém, esse aspecto deveria ser trabalhado e discutido com a equipe, para não gerar angústia, sentimento de impotência, negação e distanciamento. ${ }^{5} 0$ cuidado de pessoas com a possibilidade de morte iminente ou fora de possibilidades terapêuticas de cura, geralmente leva os profissionais a encarar a sua própria finitude, afastando-os ainda mais desse convívio como uma forma de auto-proteção. ${ }^{1}$

Os resultados revelam que, muitas questões interferem no desenvolvimento do cuidado humanizado em UTI. A manutenção de uma postura reflexiva sobre o tema é fundamental para a busca de estratégias que permitam, aos profissionais de enfermagem, ampliar seu olhar sobre o próprio processo de trabalho, a fim de tornar a humanização uma realidade possível.

\section{DISCUSSÃO}

O PNHAH define que, humanizar é resgatar a importância dos aspectos subjetivos e sociais, indissociáveis dos aspectos físicos na intervenção em saúde, respeitando o outro como ser humano autônomo e digno; é assumir uma postura ética que respeite a singularidade das necessidades do usuário e do profissional, que acolha o desconhecido e o imprevisível, que aceite os limites de cada situação. ${ }^{4}$

Para que a implementação da humanização, no cenário hospitalar, aconteça de fato, as publicações apontam ser necessário entender que, esse processo, precisa estar voltado não só ao paciente internado e aos seus familiares, mas também à própria equipe de saúde, no sentido de valorizá-la e empoderá-la para o desenvolvimento de um cuidado mais humano, ético e solidário. A humanização, portanto, precisa ser considerada uma construção coletiva que acontece a partir da identificação das potencialidades, necessidades, interesses e desejos dos sujeitos envolvidos, bem como da criação de redes interativas, participativas e solidárias entre as várias instituições que compõem o Sistema Único de Saúde. ${ }^{11}$

Com base nisso, a PNH precisa ser compreendida, não somente como uma política inerte, mas como um conjunto de referenciais e instrumentos que, em meio aos processos de trabalho, auxiliem a desequilibrar os arranjos já instituídos, instigando novas composições, outras possibilidades de ser e trabalhar no âmbito da saúde. É preciso 


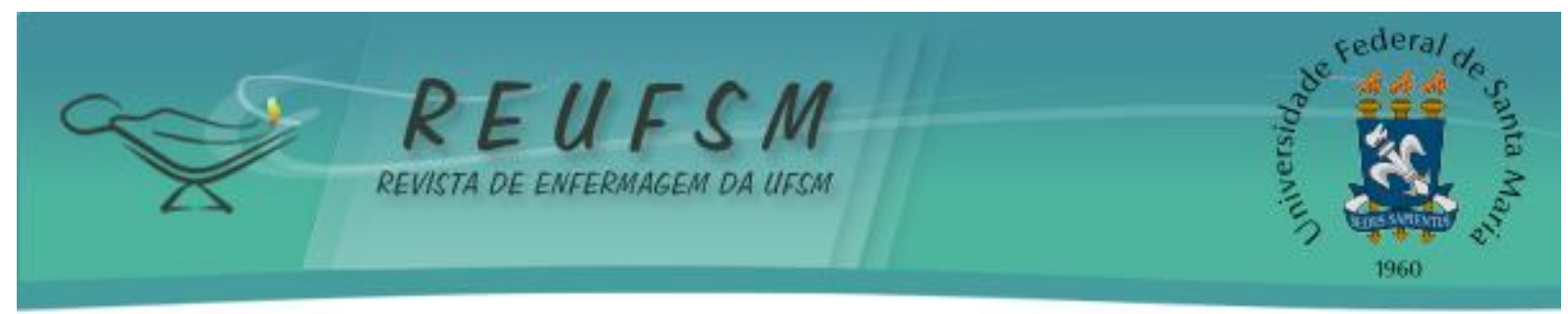

potencializar outros modos de trabalhar, que emergem do cotidiano, partindo do que é experimentado pelo trabalhador. ${ }^{14}$

Por outro lado, as publicações referendam a constatação de que, trabalhar no ambiente da UTI exige dos profissionais um grande conhecimento técnico-científico, bem como constantes atualizações, já que, a cada dia, novos instrumentais tecnológicos são incorporados, para uma melhor e mais eficaz assistência aos pacientes críticos. No entanto, reforçam também a necessidade de estes trabalhadores terem características especiais, para poderem atuar neste ambiente hostil, de forma a buscar a humanização da assistência. Dessa forma, é necessário alicerçar o processo de trabalho a novas concepções, no intuito de (re)orientar as ações desenvolvidas por estes trabalhadores, em prol da humanização da assistência.

Nesse sentido, a PNHAH traz em sua estrutura a concepção de ambiência, a qual tem relação com o espaço físico, também entendido como social, profissional e de relações interpessoais, devendo proporcionar atenção acolhedora, humana e resolutiva, considerando alguns elementos que atuam como catalisadores da inter-relação homem $x$ espaço. Entende que o espaço de trabalho possibilita uma reflexão sobre a produção do sujeito e o processo de trabalho, tendo uma conotação ética, estética e política. Ao elencar uma série de aspectos que devem ser considerados (luminosidade, odores, cores, sons, dentre outros), reitera que, ao entrar no ambiente de trabalho em saúde, o trabalhador tende a deixar de fora tudo que é relativo ao seu mundo, perdendo as referências sobre o seu cotidiano, sua cultura e seus desejos. Neste sentido, o esforço desta proposta está em resgatar esse vínculo para junto do processo de produção de saúde, tendo em vista o histórico de assistência à saúde focado na atenção às doenças, nos procedimentos e tarefas. $^{4}$

Outro aspecto marcante, nas publicações, está relacionado ao uso de recursos tecnológicos, que são imprescindíveis para a assistência qualificada à saúde de pacientes críticos, mas que tem tido certa supremacia em relação à utilização de outras formas de cuidado. Nesse sentido, é importante questionar sobre a forma como este instrumental tecnológico tem sido apresentado a acadêmicos e trabalhadores da enfermagem, a qual, muitas vezes, traz implícita a idéia de que tais instrumentais são tão necessários à sobrevivência dos pacientes que sobrepujam outras formas de cuidado. Além disso, a que se considerar que, os cursos de formação em enfermagem, ainda utilizam-se pouco de estratégias de ensino que despertem nos futuros profissionais características como sensibilidade, habilidade de interação, de comunicação não verbal, dentre outras.

o fato de o contexto de uma unidade de terapia intensiva suscitar, nos acadêmicos, a idéia de um campo riquíssimo para o aprendizado de procedimentos técnicos e de recursos tecnológicos pode resultar em uma supervalorização desses aspectos em detrimento de outros, como os relacionais, também fundamentais para o cuidado de enfermagem. Além disso, o fato de os pacientes críticos, muitas vezes, não manifestaremse verbalmente, aliado ao temor expresso por muitos acadêmicos em comunicarem-se com pacientes comatosos ou sedados, interfere no estabelecimento de um cuidado mais interativo com os pacientes.

Com isso, depreende-se que, a implementação da humanização do cuidado ao paciente internado em UTI envolve uma série de fatores, não podendo ser analisada isoladamente. Há necessidade urgente de uma ampla revisão desde o processo formativo até o processo de trabalho dos profissionais da enfermagem, no sentido de buscar-se o desenvolvimento de habilidades que possam facilitar o processo interativo com pacientes e familiares. Da mesma forma, acredita-se que a efetivação da humanização do cuidado também está atrelada ao comprometimento institucional com diferentes formas de cuidar, que valorizem outros aspectos além de um trabalho normativo e prescritivo, alicerçado a 


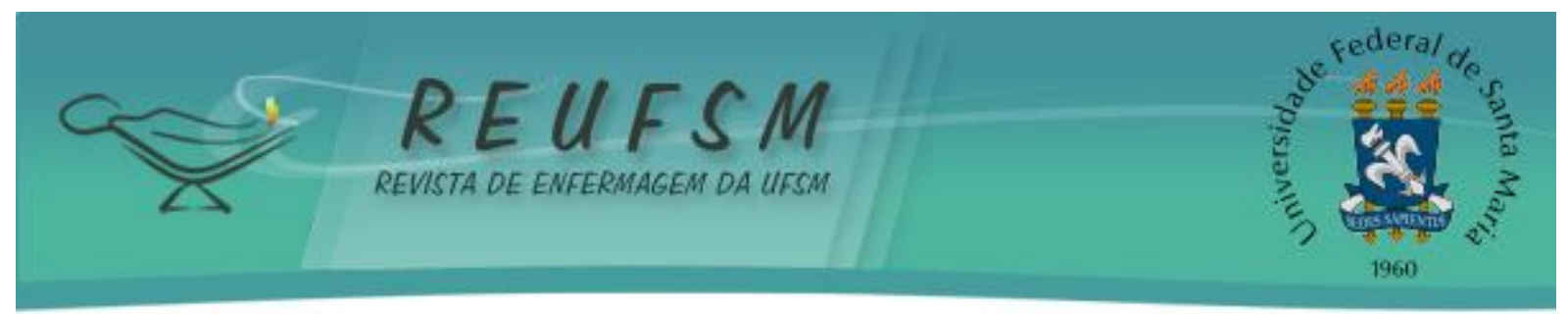

um modelo curativista.

\section{CONSIDERAÇÕES FINAIS}

Após a análise dos textos pode-se notar que, o processo de implementação da humanização na UTI, ainda é um longo caminho a ser percorrido. Os profissionais da equipe de saúde, muitas vezes, encontram-se sobrecarregados, o que gera um acúmulo de tarefas levando o profissional a executá-las mecânica e sistematizadamente, causando um distanciamento entre ele, o paciente e sua família.

As publicações também evidenciam que não basta pensar em humanização com enfoque apenas ao paciente, é preciso pensar também na equipe que presta o cuidado, a humanização só será possível se os profissionais da equipe se sentirem humanizados, valorizados, motivados com o trabalho que exercem e se realmente internalizarem a importância e se sentirem protagonistas desse processo na UTI.

No entanto, tendo em vista que se trata de um estudo bibliográfico, com base em artigos nacionais, compreendemos que essa análise acaba ficando bastante restrita, sendo essa a principal limitação do mesmo. Nesse sentido, apontamos, como principal sugestão, a realização e ampla divulgação de estudos, que possam aprofundar a análise dessa temática, incluindo sua discussão no âmbito dos espaços de formação profissional e de educação em serviço, no intuito de expandir o processo reflexivo sobre a importância da humanização em unidade de terapia intensiva.

Por fim, entendemos que uma aproximação efetiva com os pressupostos da PNH, por parte das instituições e profissionais da saúde, e, particularmente, para os da enfermagem, é essencial para alavancar-se um processo de reflexão sobre o tema e buscar-se, efetivamente, a humanização do cuidado em UTI.

\section{REFERÊNCIAS}

1. Silva GF, Sanches PG, Carvalho MDB. Refletindo sobre o cuidado de enfermagem em unidade de terapia intensiva. Rev Min Enferm. 2007;11(1):94-98.

2. Pinho LB, Santos SMA. Dialética do cuidado humanizado na UTI: contradições entre o discurso e a prática profissional do enfermeiro. Rev Esc Enferm USP. 2008; 42(1):66-72.

3. Nascimento ERP, Trentini M. O cuidado de enfermagem na unidade de terapia intensiva (UTI): teoria humanística de Paterson e Zderad. Rev Latino-am Enfermagem. 2004; 12(2):250-7.

4. Brasil. Ministério da Saúde. Programa Nacional de Humanização da Assistência Hospitalar. Brasília: Ministério da Saúde; 2001.

5. Vila VSC, Rossi LA. O significado cultural do cuidado humanizado em unidade de terapia intensiva: "muito falado e pouco vivido". Rev. Latino-am Enfermagem. 2002; 10(2):137-44.

6. Lopes ALM; Fracolli LA. Revisão sistemática de literatura e metassíntese qualitativa: considerações sobre sua aplicação na pesquisa em enfermagem. Texto Contexto Enferm. 2008; 17(4):771-8.

7. Silva RC, Ferreira MA. Representações sociais dos enfermeiros sobre a tecnologia no ambiente da terapia intensiva. Texto Contexto Enferm. 2009; 18(3):489-97.

8. Nascimento KC, Erdmann AL. Cuidado transpessoal de enfermagem a seres humanos em unidade crítica. R Enferm UERJ. 2006; 14(3):333-41. 


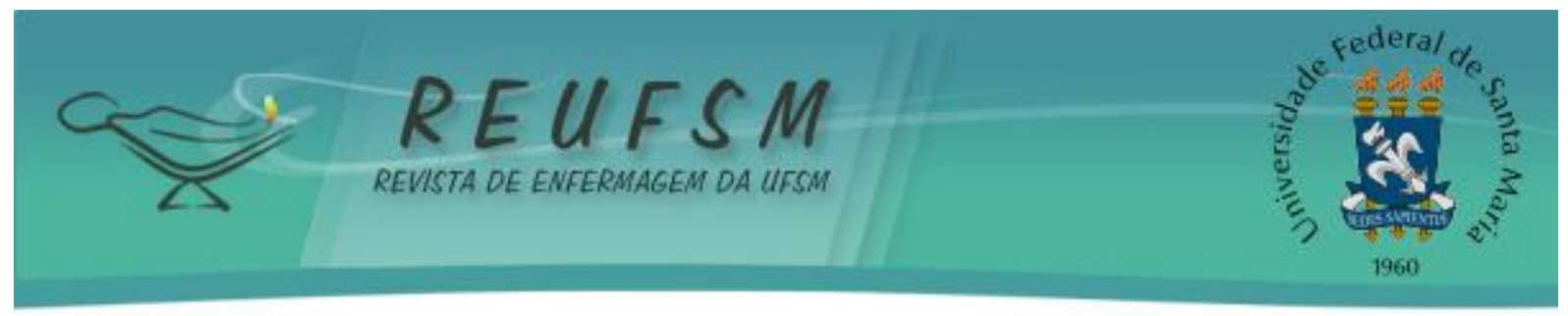

9. Caetano JA, Soares E, Andrade LM, Ponte RM. Cuidado humanizado em terapia intensiva: um estudo reflexivo. Esc Anna Nery R Enferm. 2007; 11(2):325-30.

10. Salicio DMB, Gaiva MAM. O significado de humanização da assistência para enfermeiros que atuam em UTI. Rev Eletr Enf UFG. 2006; 8(3):370-6.

11. Costa SC, Figueiredo MRB, Schaurich D. Humanização em unidade de terapia intensiva adulto (UTI): compreensões da equipe de enfermagem. Interface - Comunic, Saúde, Educ. 2009; 13(1):571-80.

12. Amestoy SC, Schwartz E, Thofehrn MB. A humanização do trabalho para os profissionais de enfermagem. Acta Paul Enferm. 2006; 19(4):444-9.

13. Silva RCL, Porto IS, Figueiredo NMA. Reflexões acerca da assistência de enfermagem e o discurso de humanização em terapia intensiva. Esc Anna Nery Rev Enferm. 2008;12(1):156-9.

14. Santos Filho SB, Barros MEB, Gomes RS. A política nacional de humanização como política que se faz no processo de trabalho em saúde. Interface - Comunic, Saude, Educ. 2009;13(1):603-13.

Data de recebimento: $11 / 11 / 2010$

Data de aceite: $22 / 12 / 2010$

Contato com autora responsável: Silviamar Camponogara

E-mail: silviaufsm@yahoo.com.br. 